\title{
DIELECTRIC PARAMETERS OF THE MODERN LOW-LOSS CERAMICS IN THE MICROWAVE, MILLIMETER, AND SUBMILLIMETER RANGES
}

Vladimir V. Parshin ${ }^{1}$, Evgeny A. Serov ${ }^{1}$, Evgeny E. Chigryai ${ }^{2}$, Boris M. Garin ${ }^{2}$, Roman N. Denisiuk ${ }^{2}$, Dmitry S. Kalyonov ${ }^{2}$, Mingqing Ding ${ }^{3}$, Lili Li ${ }^{3}$, Yanping $\mathrm{Lu}^{3}$, Yanling Yang ${ }^{3}$, Youhuan Liang ${ }^{3}$, Jinjun Feng ${ }^{3}$, and Polina V. Ershova ${ }^{4}$

${ }^{1}$ Institute of Applied Physics of Russian Academy of Sciences, 603950, Nizhny Novgorod, Russia

${ }^{2}$ Fryazinio Branch of Kotelnikov Institute of Radioengineering and Electronics of Russian Academy of Sciences, Vvedensky Sq.1, Fryazino Moscow region 141190, Russia

${ }^{3}$ Vacuum Electronics National Lab, Beijing Vacuum Electronics Research Institute, 100015, Beijing, China

${ }^{4}$ Public Corporation "Magneton", 194223, St.-Petersburg, Russia

The paper is received on February 15, 2018

Abstract. The dielectric parameters in a very wide frequency range $10-350 \mathrm{GHz}$ in the modern low-loss ceramics, the aluminum nitride $\mathrm{AlN}$ and aluminum oxide $\mathrm{Al}_{2} \mathrm{O}_{3}$, fabricated in China and Russia, are investigated. The measurements of the refractive index and dielectric loss tangent were conducted using different techniques and measurement setups. For the measurement of dielectric loss in the microwave range, at frequency of $9.4 \mathrm{GHz}$, the closed metal cavity resonator was used. For the measurements of refractive index in the millimeter (MM) and submillimeter (SubMM) ranges, at the frequencies of $60-350 \mathrm{GHz}$, both open resonators and scalar network analyzers were used. For the measurements of dielectric loss in the MM and SubMM ranges different open resonators were used.

The refractive index and dielectric loss were measured at $f=70-350 \mathrm{GHz}$. in three Chinese samples of ceramic AlN and two samples of ceramic $\mathrm{Al}_{2} \mathrm{O}_{3}$. In all samples the losses are very low: $\tan \delta<10^{-3}$. Also the dielectric loss was measured in newest Russian sample of ceramic $\mathrm{Al}_{2} \mathrm{O}_{3}$, fabricated in the PC "Magneton" (of the brand "VK100M"). The loss in it is the lowest loss observed among ceramics $\mathrm{Al}_{2} \mathrm{O}_{3}$. Moreover, this loss is only slightly higher, that in the corresponding single crystal (sapphire).

The nature of observed losses is considered. The loss frequency dependencies in the $\mathrm{MM}$ and SubMM ranges in all ceramics $\mathrm{Al}_{2} \mathrm{O}_{3}$ studied can be well described by 
the linear approximation. Such dependence corresponds to the mechanism of socalled one-phonon lattice loss induced by the crystal lattice disorder.

Key words: dielectric loss, refractive index, low loss ceramics, microwave, millimeter, and submillimeter ranges, open resonators.

\section{Introduction}

The study of dielectric parameters of low-loss ceramics and technological possibilities of their improvement is a very actual problem [1-3]. It currently has a considerable attention in Russia and China. It is associated in particular with the problem of the development of the element base of high-power electronics in microwave, millimeter (MM), and submillimeter (SubMM) ranges. The low loss ceramics are of great interest in this area for use as relatively inexpensive materials for using as matching elements in various energy coupling systems in the vacuum electronic devices.

The refractive index and dielectric loss in a wide frequency range $10-350 \mathrm{GHz}$ in the modern low-loss ceramics aluminum nitride $\mathrm{AlN}$ and aluminum oxide $\mathrm{Al}_{2} \mathrm{O}_{3}$, fabricated in China and Russia, are investigated at this work. The samples of ceramics are provided by Beijing Research Institute of Vacuum Electronics (BVERI) and Public Corporation "Magneton" (St.-Petersburg). The measurements of the refractive index and dielectric loss were conducted using different methods and measurement setups in the PC "Magneton" [1, 2], Institute of Applied Physics of RAS (IAP) [3-8], and Fryazino branch of the Kotel'nikov Institute of Radioengineering and Electronics of RAS (FIRE) [9, 3].

The nature of observed losses in some materials is considered.

\section{Methods for measuring dielectric loss and refractive index}

Measurement of the dielectric loss tangent $\tan \delta$ in the microwave range, at frequency of $9.4 \mathrm{GHz}$, was performed by using the closed metal cavity resonator in the PC "Magneton" [1, 2]. 
Studies of dielectric parameters (dielectric loss tangent $\tan \delta$ and refractive index $n)$ in the millimeter (MM) and submillimeter (SubMM) ranges were carried out at the IAP using the spectrometer on the basis of the open resonator Fabry-Perot (with the quality-factor $Q \sim 10^{6}$ ) formed by two spherical mirrors. The resonator is excited by the Back-Wave Oscillators (BWO). A more detailed description of the measurement techniques is presented in [4-6]. And the measurement setup and its specifications are presented in $[7,8]$.

In FIRE for the measurement of the refractive index a scalar network analyzer, operating in the frequency band $120-180 \mathrm{GHz}$, was used. The measurement technique is described in [9]. For the measurement of the dielectric loss in the longwave part of the MM range, at the frequency of $69.4 \mathrm{GHz}$, a compact open semisymmetric confocal resonator was used. It was excited by the generator based on the Gann's diode at the frequency of $69.4 \mathrm{GHz}$. This measurement technique and setup are described in [9]. And in the present work the following was taken into account. The values of the thickness in the samples that was investigated in the present work were more than half of the wave length in the dielectric material. And in the calculating of the quality-factor of the resonator with placed in it a sample in the form of a plane-parallel dielectric plate there is a need to consider an additional increase in the optical length of the resonator (taking into account the double passage of the wave through the plate) on the value $2 n h$. This technique has the following two advantages compared with the methods in [4-8]. It provides an opportunity to measure the loss in the long-wave part of the millimeter range in samples of smaller diameter compared with the methods in [4-8]. In addition, it allows measure the loss at arbitrary ratio between the sample thickness and the wavelength in the dielectric.

\section{Results and discussion}

The refractive index and dielectric loss of the following ceramic samples, fabricated in BVERI, were investigated: three samples of aluminum nitride $\mathrm{AlN}$ and two samples aluminum oxide $\mathrm{Al}_{2} \mathrm{O}_{3}$. They and their geometrical parameters are presented in the Fig. 1. 
AIN samples

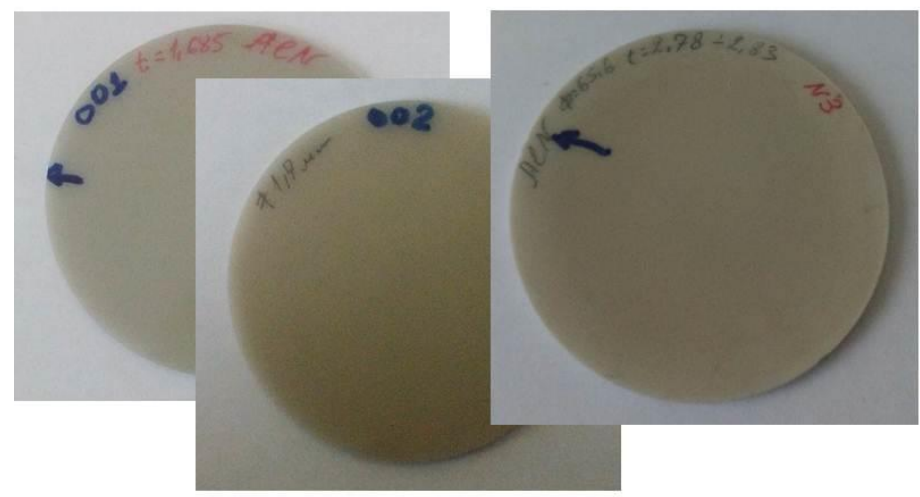

$\mathrm{Al}_{2} \mathrm{O}_{3}$ samples

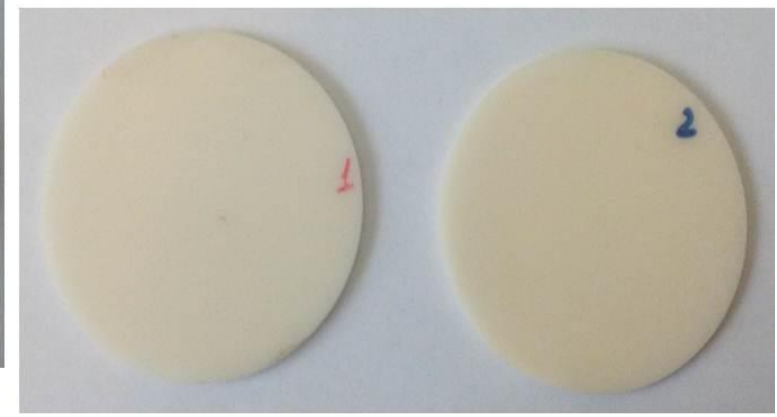

Sample \#1: diameter - $64 \mathrm{~mm}$, thickness $-1,685 \mathrm{~mm}$; Sample \#2: diameter $-64 \mathrm{~mm}$, thickness $-1,69 \mathrm{~mm}$; Sample \#3: diameter $-65,6 \mathrm{~mm}$, thickness $-2,81 \mathrm{~mm}$;
Sample \#1: diameter $-\mathbf{5 2} \mathrm{mm}$, thickness $-\mathbf{2 , 1 2 5} \mathrm{mm}$ Sample \#2: diameter $-52 \mathrm{~mm}$, thickness $-\mathbf{2 , 1 3 5} \mathrm{mm}$

Fig. 1. Ceramic AlN and $\mathrm{Al}_{2} \mathrm{O}_{3}$ samples from BVERI.

\subsection{Refractive index}

In the Table 1 the refractive index $n$ and the thickness of samples $h$ of the Chinese samples of ceramics $\mathrm{AlN}$ and $\mathrm{Al}_{2} \mathrm{O}_{3}$, measured in FIRE and IAP, are presented.

Table 1. Refractive index in Chineese ceramics $\mathrm{AlN}$ and $\mathrm{Al}_{2} \mathrm{O}_{3}$.

\begin{tabular}{|l|c|l|c|c|}
\hline \multirow{2}{*}{ Sample } & \multicolumn{2}{|c|}{ FIRE } & \multicolumn{2}{c|}{ IAP } \\
\cline { 2 - 5 } & $N$ & \multicolumn{1}{c|}{$h, \mathrm{~mm}$} & $n$ & $h, \mathrm{~mm}$ \\
\hline AlN № 1 & 2.88 & 1.685 & $2.917 \pm 0.004$ & 1.68 \\
\hline AlN № 2 & 2.875 & 1.69 & $2.921 \pm 0.004$ & 1.68 \\
\hline $\mathrm{AlN}$ № 3 & 2.712 & 2.81 & $2.885 \pm 0.004$ & 2.77 \\
\hline $\mathrm{Al}_{2} \mathrm{O}_{3}$ № 1 & 3.134 & 2.125 & $3.160 \pm 0.001$ & 2.1 \\
\hline $\mathrm{Al}_{2} \mathrm{O}_{3}$ № 2 & 3.129 & 2.135 & & 2.1 \\
\hline
\end{tabular}

As it can be seen from the Table 1, the values of the thickness $h$ of the samples and the refractive index $n$ from the measurements in FIRE and IAP are close to each other, but are slightly different. These differences can be explained by differences in methods of measurement of the thickness of the samples. It should be noted that the samples are not perfectly plane-parallel. There are distortions of the "meniscus" of up to $10 \mu \mathrm{m}$ and a wedge on the edge of the disc is $\sim 15 \mu \mathrm{m}$. Therefore, the accuracy of the measurement of the refractive index is not the maximum possible. The thickness of the disks are given for their centers. 
The change of refractive index with frequency in the considered frequency range does not exceed the measurement error.

\subsection{Dielectric loss}

\section{Dielectric loss in three Chinese samples of AlN.}

The frequency dependencies of $\tan \delta$, measured in IAP, are shown in Fig. 2. In the frequency range of $f \sim 70-350 \mathrm{GHz}$ the loss tangent $\tan \delta$ changes in the range (5$8) \cdot 10^{-4}$. And there is a local minimum near $f \sim 150 \mathrm{GHz}$. Previous investigations of a series of samples "Degussit AlN180" of the company "Frinatec" (Germany) provides a similar results in the same frequency range as the magnitude of the index of refraction and $\tan \delta$. There also a local minimum near the same frequencies $f \sim 150-160$ $\mathrm{GHz}$ is observed.

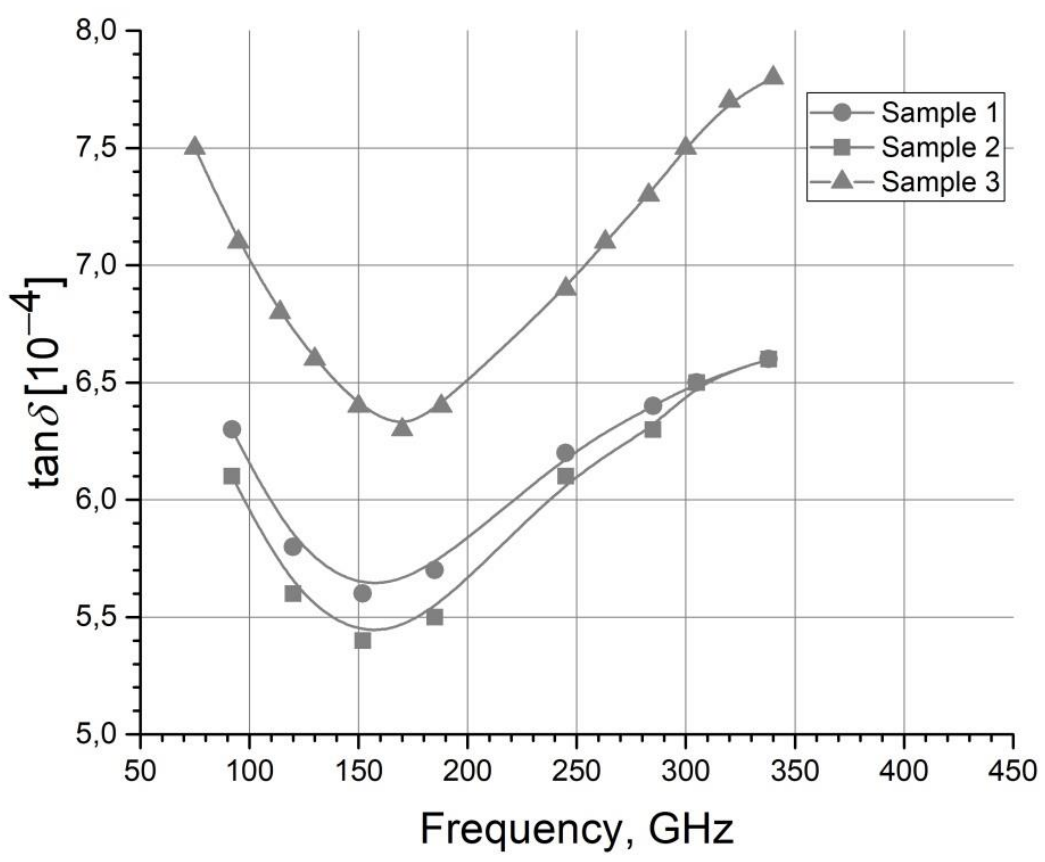

Fig. 2. The dependence of $\tan \delta$ with frequency for the samples of aluminum nitride (AlN).

The dielectric loss measured in FIRE in the samples of AlN No. 1 and 2 at the frequency of $69.4 \mathrm{GHz}$ are shown in the Table 2. 
Table 2.The loss measured in FIRE in the samples of AlN No. 1 and 2 at the frequency of $69.4 \mathrm{GHz}$

\begin{tabular}{|c|c|}
\hline Sample & $\tan \delta\left[10^{-4}\right]$ \\
\hline 1 & 6,1 \\
\hline 2 & 6,0 \\
\hline
\end{tabular}

The values for the loss tangent found from measurements in FIRE are close to the data found in IAP for the samples No. 1 and No. 2 in Fig. 2 at the same frequency.

\section{Dielectric loss in the ceramic $\mathrm{Al}_{2} \underline{O}_{3}$}

The loss frequency dependencies in two ceramic samples of aluminum oxide $\mathrm{Al}_{2} \mathrm{O}_{3}$ of Chinese production at the frequency band of $90-360 \mathrm{GHz}$, measured in IAP, are shown in Fig. 3. The data for these two samples are practically identical within the error of measurements.

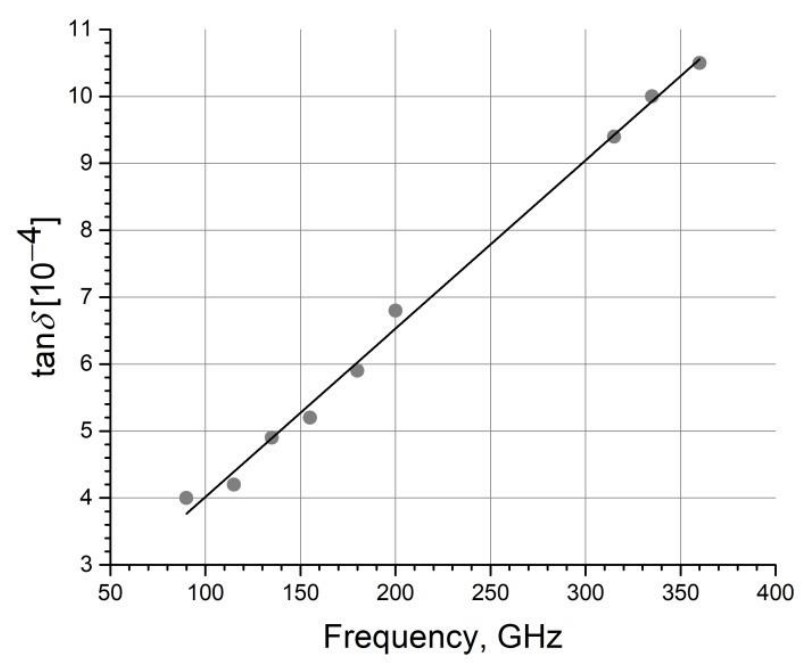

Fig. 3. The frequency dependence of the loss tangent in the Chinese ceramics $\mathrm{Al}_{2} \mathrm{O}_{3}$.

For a comparison, in the Fig. 4 the data are presented from measurement in IAP for the dielectric loss in the sample of the newest Russian ceramic $\mathrm{Al}_{2} \mathrm{O}_{3}$ of the brand VK100M that was fabricated in the PC "Magneton".

The measurement in microwave range at the frequency of $9.4 \mathrm{GHz}$ was made in the "Magneton", and the measurements at the band of 60-200 GHz were made in IAP. 


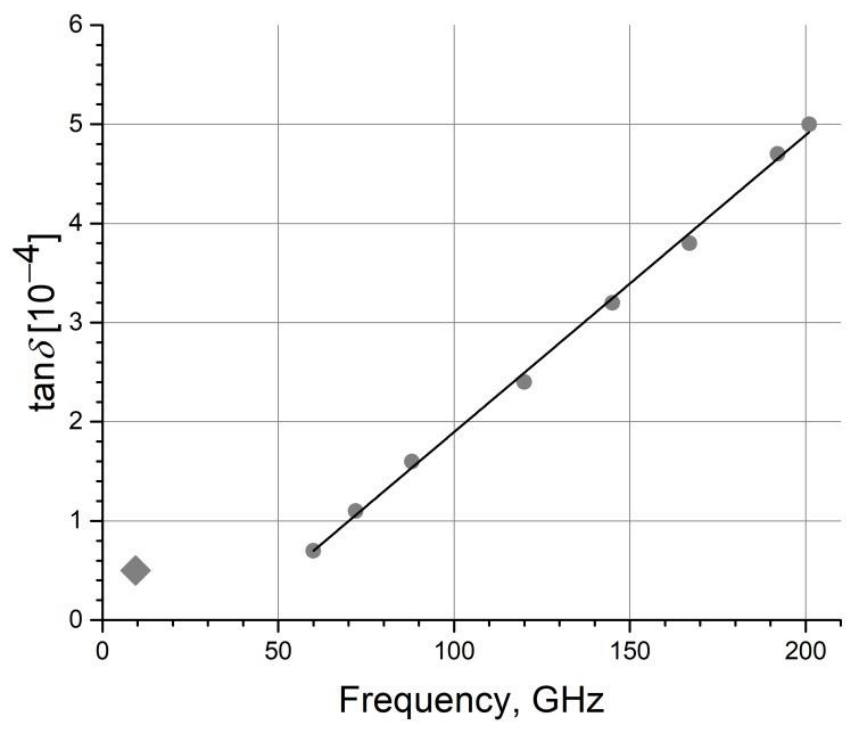

Fig. 4. The loss frequency dependence in the sample ceramic $\mathrm{Al}_{2} \mathrm{O}_{3} \mathrm{VK} 100 \mathrm{M}$ of the Russian production.

The frequency dependencies in the Fig. 3 and 4 at MM and SubMM ranges can be well described by the linear approximation. Such dependence corresponds to the mechanism of the so-called one-phonon lattice loss induced by lattice disorder [8, 9]. In this mechanism, the absorption of one photon is accompanied by the excitation of one acoustic phonon.

The loss in the Fig. 4 at the microwave range (at the frequency of $9.4 \mathrm{GHz}$ ) deviates significantly from the mentioned linear dependence. This is a sign that in the microwave range the loss is due to another mechanism. It can be connected with the Debye's dipole relaxation process in the disordered transitional borders between crystallites in the ceramic. Such process is observed in many disordered substances, usually at relatively lower frequencies compared to the frequency range considered in the present work [12].

The comparison between the studied samples of the ceramics $\mathrm{Al}_{2} \mathrm{O}_{3}$ of the Chinese and Russian production shows that in the first the loss is higher. It can be due to a different manufacturing technology or insufficient purity of the used aluminum and other components. 
The loss in the sample of newest Russian ceramic $\mathrm{Al}_{2} \mathrm{O}_{3} \mathrm{VK} 100 \mathrm{M}$ is the lowest loss observed among ceramics $\mathrm{Al}_{2} \mathrm{O}_{3}$. Moreover, it is quite close to the loss in the corresponding single crystal (sapphire): $\tan \delta \approx 3.4 \cdot 10^{-4}$ and $2.3 \cdot 10^{-4}$ at $f=150 \mathrm{GHz}$ respectively.

\section{Conclusions}

1. As a result of conducted research it can be concluded that a number of investigated ceramics with very low loss $\tan \delta<10^{-3}$ are suitable for use in the MM and SubMM ranges to improve the various structures that interact with electromagnetic wave including components for energy transfer in the systems of vacuum electronic devices in high-power electronics in these ranges.

2. The loss in the sample of newest Russian ceramic $\mathrm{Al}_{2} \mathrm{O}_{3} \mathrm{VK} 100 \mathrm{M}$ is the lowest loss observed among ceramics $\mathrm{Al}_{2} \mathrm{O}_{3}$, and it is quite close to the loss in the corresponding single crystal (sapphire).

\section{Acknowledgement}

The work was partially supported by the Russian Foundation for Basic Research (project No. 16-52-53140) and the Chinese State Foundation of Natural Sciences.

\section{References}

1. Firsenkov A.I., Kanivets A.Yu., Kasatkina T.S., Ershova O.M., Ivanova L.P., Ershova P.V., Microwave dielectric materials fabricated in the PC "Magneton", Sbornic statei IV Vserossiiskoi Konferentsii "Elektronica i Mikroelektronika SVCh" [Collection of papers of the Fourth All-Russian Conf. "Microwave Electronics and Microelectronics"] Saint-Petersburg, publishing of the Saint-Petersburg State Electrical-engineering University “LETI”, 2015, Vol. 2, pp. 55-59.

2. Parshin V.V., Serov E.A., Ershova P.V., The study of dielectric properties of modern ceramic materials in the millimeter range, Sbornic statei Shestoi Vserossiiskoi Konferentsii "Elektronica i Mikroelektronika SVCh" [Collection of papers of the Sixth All-Russian Conf. "Microwave Electronics and 
Microelectronics"] Saint-Petersburg, publishing of the Saint-Petersburg State Electrical-engineering University “LETI”, 2017, pp. 418-422.

3. Parshin V.V., Serov E.A., Chigryai E.E., Garin B.M., Denisyuk R.N., Kalyonov D.S., Li L., Feng J., Ershova P.V. Dielectric parameters of newest low absorption ceramics in microwave and millimeter ranges. $V$ Vserossiiskaya mikrovolnovaya Konferntsiya, Doklady [Proc. of Fifth All-Russian Microwave Conference], Moscow, Kotel'nikov IRE of RAS, November 29 - December 1, 2017, pp. 226-230. Publ.: Kotel'nikov IRE of RAS, 2017.

4. Dryagin Yu.A., Parshin V.V., A method for determination of dielectric permittivity and loss tangent. The Copyright Certificate No. 1539681, Bulletin No. 40, The USSR State Committee for inventions and discoveries, 1990, January 30.

5. Dryagin Yu.A., Parshin V.V. A method to measure dielectric parameters in $5 \div 0,5 \mathrm{~mm}$ wavelength band. International Journal of Infrared and Millimeter Waves, 1992, Vol. 13, No.7, pp.1023-1032.

6. S.N. Vlasov, E.V. Koposova, A.B. Mazur and V.V. Parshin. On permittivity measurement by a resonance method. Radiophysics and Quantum Electronics, 1996, Vol. 39, No. 5, pp. 410-415.

7. Parshin V.V., Tretyakov M.Yu., Koshelev M.A., Serov E.A. Instrumental complex and the results of precise measurements of MM and SubMM wave propagation in condensed media and atmosphere. Radiophysics and Quantum Electronics, 2012, Vol. 52, No. 8, pp. 525-535. DOI:10.1007/s11141-010-9169-0

8. Parshin V.V., Tretyakov M.Yu., Koshelev M.A., Serov E.A., Modern resonator spectroscopy at submillimeter wavelengths. IEEE Sensors Journal, 2013, Vol. 13, No 1, pp. 18-23.

9. E.E. Chigryai, B.M. Garin, R. N. Denisyuk, D. S. Kalenov, I. P. Nikitin. Ultralow absorption in silicon carbide in the millimeter wave range", Zhurnal Radioelektroniki - Journal of Radio Electronics, 2016, No. 11. Available at http://jre.cplire.ru/jre/nov16/6/text.pdf.

10. B.M Garin, "One-phonon dielectric c losses by excitation of sound". Sov. Phys. Solid State 32 (11) (1990) 1917-1920. 
11. B.M. Garin, "Disorder-induced one-phonon absorption of millimeter and submillimeter waves", SPIE Proc. Vol. 2211b, USA, 1994, pp. 606-614.

12. A.R. Hippel, Dielectrics and Waves, N.-Y., John Willey \& Sons, 1954.

\section{For citation:}

Vladimir V. Parshin, Evgeny A. Serov, Evgeny E. Chigryai, Boris M. Garin, Roman N. Denisiuk, Dmitry S. Kalyonov, Mingqing Ding, Lili Li, Yanping Lu, Yanling Yang, Youhuan Liang, Jinjun Feng, and Polina V. Ershova. Dielectric parameters of the modern low-loss ceramics in the microwave, millimeter, and submillimeter ranges. Zhurnal Radioelektroniki - Journal of Radio Electronics. 2018. No. 2. Available at http://jre.cplire.ru/jre/feb18/10/text.pdf. 